\title{
ВИЗНАЧЕННЯ НЕСУЧОЇ ЗДАТНОСТІ НОРМАЛЬНИХ ПЕРЕРІЗІВ КОМБІНОВАНО-АРМОВАНИХ СТАЛЕФІБРОБЕТОННИХ ЗГИНАЛЬНИХ ЕЛЕМЕНТІВ
}

\section{CALCULATION OF BEARING CAPACITY OF NORMAL CROSS- SECTIONS OF COMBINED-REINFORCED SFRC BENDING ELEMENTS}

Андрійчук О.В., к.т.н., доц., Кислюк Д.Я., к.т.н., доц., Нінічук М.В., аспірант (Луцький національний технічний університет, м Луцьк)

Andriichuk O.V., Ph.D. in Engineering, Associate Professor, Kysliuk D.Y., Ph.D. in Engineering, Associate Professor, Ninichuk M.V., postgraduate student, (Lutsk National Technical University, Lutsk)

Анотація. Удосконалено методику розрахунку несучої здатності комбіновано-армованих сталефібробетонних елементів за допомогою врахування спрощених діаграм деформування сталефібробетону на стиск і на розтяг.

Summary. In recent years, the scope of application of reinforced concrete and combined-reinforced structures in load-bearing structures is expanding. Studies by many authors indicate the significant advantages of reinforced concrete and combinedreinforced bending elements over the classic reinforced concrete. Current state regulations do not take into account all the properties of reinforced concrete, and therefore the load-bearing capacity of structures can in many cases be underestimated. Therefore, it is advisable to take into account, when calculating, all the properties of this material.

The current state standards for the calculation and design of reinforced concrete structures are based on the fact that reinforced concrete is considered as one of the types of disperse-reinforced material. However, with this approach, many factors are taken into account, the value of which, in real conditions, can be in a wide range of values, so they are taken into account with a margin.

The article proposes a simplified force method for calculating the bearing capacity of combined-reinforced reinforced concrete bending elements. Simplified diagrams of deformation of reinforced concrete under compression and tensile obtained on the basis of experimental tests are taken into account. The tensile diagram is proposed to be threeline. To evaluate the effectiveness of the method and study a number of other characteristics, two series of experimental studies of inseparable combined - reinforced concrete beams were performed. Research methods and the nature of the beams in the test process, described in [8-10]. For comparison with the obtained experimental data, the article presents the calculation of experimental beams, performed according to state standards and a simplified force method.

The results show that when determining the load-bearing capacity of the section, the results determined by a simplified force model show the best agreement with the 
experimental ones. It is obvious that taking into account the full operation of reinforced concrete in compression and tension, increases the accuracy of the calculation. The average error is $3 \ldots 5 \%$.

Ключові слова: бетон, сталева фібра, СФБ, розрахунок, деформачій, несуча здатність.

Keywords: concrete, steel fiber, SFRC, calculation, strain, bearing capacity.

Постановка проблеми. Останніми роками розширюється сфера застосування сталефібробетонних і комбіновано-армованих конструкцій у цивільному та промисловому будівництві. Найчастіше сталефібробетон використовують у конструкціях підлог, доріг, елементах водовідвідних інженерних мереж, а також розширюється його застосування в несучих елементах будівель і споруд. Однак, незважаючи на накопичений значний експериментальний досвід і велику кількість досліджень елементів із сталефібробетону, до розрахунку таких конструкцій підходять із деякою обережністю. Чинні державні будівельні норми не враховують усіх властивостей сталефібробетону, а тому несуча здатність конструкцій у багатьох випадках може бути недооцінена.

Аналіз відомих досліджень і публікацій. Дослідження роботи сталефібробетонних конструкцій та особливостей їх напруженодеформованого стану проводились багатьма вченими. Бабичем Є.М. із Дробишинцем С.Я. було встановлено напружено-деформований стан сталефібробетонних i комбіновано-армованих балок при одноразових i повторних малоциклових навантаженнях [1]. Ними досліджувався вплив відсотка армування сталевою фіброю на характеристики НДС балок, була запропонована деформаційна методика розрахунку такого типу елементів. Вченим Білозіром В.В. [2] досліджувалися утворення та розкриття нормальних тріщин згинальних сталефібробетонних i комбінованоармованих елементів із армуванням фіброю 3 листа. Дослідження міцності, деформативності та тріщиностійкості СФБ елементів кільцевого перерізу при одноразовому та повторному навантаженні, а також напружено-деформаційний стан цих елементів представлено в роботі [3]. Ці дослідження, а також дослідження інших авторів, вказують на суттєві переваги сталефібробетонних і комбіновано-армованих згинальних елементів над класичними залізобетонними. Тому під час розрахунку доцільним є врахування всіх властивостей цього матеріалу.

Мета статті - вдосконалити методику розрахунку комбінованоармованих сталефібробетонних згинальних елементів із врахуванням повної роботи сталефібробетону на стиск і на розтяг.

Чинні державні норми розрахунку та проектування сталефібробетонних конструкцій [4] базуються на тому, що сталефібробетон розглядається, як один із видів дисперсно-армованого матеріалу. Сталеві фібри приводяться до дисперсної арматури і міцність 
матеріалу на розтяг визначають, як добуток міцності фібри та коефіцієнтів зчеплення фібри з бетоном, орієнтації, типу і кількості фібр, що попадають в розрахунковий переріз. Однак, при такому підході, в розрахунку приймається багато факторів, величина яких у реальних умовах може знаходитися в широкому діапазоні значень, тому враховуються вони із запасом.

Несучу здатність фібробетонних і комбіновано-армованих згинальних елементів визначають, виходячи із наступних передумов:

- для перерізів вважається справедливою гіпотеза про лінійний розподіл деформацій по висоті;

- у стиснутій зоні зв'язок між напруженнями та деформаціями приймається у вигляді діаграм із ДБН В.2.6-98:2009 [5];

- у розтягнутому сталефібробетоні зв'язок між напруженнями та деформаціями описується діаграмою, що представлена на рис. 1 .

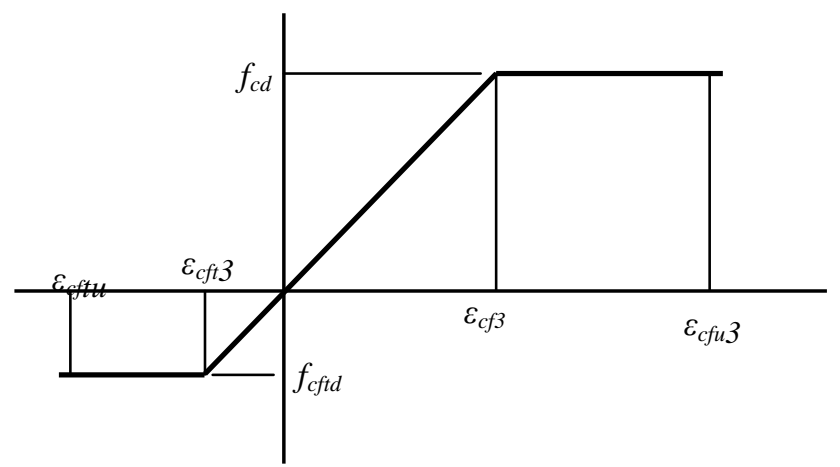

Рис. 1. Діаграма деформування сталефібробетону при розтягу, що пропонується ДСТУ-Н Б В.2.6-218:2016

Граничні деформації сталефібробетону при розтягу пропонується приймати рівними:

$$
\varepsilon_{c f t u}=\frac{1,8 f_{c f t d}}{E_{c d}},
$$

Розрахунковий опір сталефібробетону на стиск $f_{c d}$ приймають таким, що дорівнює розрахунковому опору цементно-піщаної матриці, на базі якої виготовляється сталефібробетон.

Значення граничного згинального моменту для перерізів сталефібробетонних згинальних елементів визначають рішенням наступної системи рівнянь:

$$
\frac{b f_{c d}}{\bar{\aleph}} \sum_{k=1}^{5} \frac{a_{k}}{k+1} \gamma^{k+1}-b f_{c f t d}\left(h-x_{1}-\frac{x_{1} f_{c f t d}}{2 E_{c d} \varepsilon_{c f(1)}}\right)-N=0,
$$




$$
\frac{b f_{c d}}{\bar{\aleph}^{2}} \sum_{k=1}^{5} \frac{a_{k}}{k+2} \gamma^{k+2}-\frac{1}{2} b f_{c f t d}\left(h-x_{1}\right)^{2}+\frac{1}{3} b x_{1}^{2} \frac{f_{c f t d}^{3}}{E_{c d}^{2} \varepsilon_{c f(1)}^{2}}-M=0,
$$

$$
\text { де } \gamma=\varepsilon_{c(1)} / \varepsilon_{c l} \text {; }
$$

$x_{l}=\varepsilon_{c(1)} / \aleph-$ висота стиснутої зони;

$$
\aleph=\aleph / \varepsilon_{c l}-\text { відносна кривина. }
$$

Розв'язування цієї системи нелінійних, рівнянь виконується методом підбору за критерієм вичерпання несучої здатності, 3 контролем на кожному кроці розрахунку.

Визначення граничних деформацій сталефібробетону при розтягу за формулою (1.1), при підстановці експериментально отриманих значень $f_{c f t d}$ та $E_{c d}$, дає результат приблизно рівний, а то й менший, ніж середня гранична розтягуваність бетону. Однак чисельні дослідження роботи сталефібробетонних згинальних елементів вказують на значно більший діапазон роботи сталефібробетону за розтягу при згині. Особливо у комбіновано-армованих сталефібробетонних елементах, де основні зусилля розтягу сприймає стержнева арматура.

Для європейських норм, асоціацією RILEM пропонується ідеалізовану діаграму при розтягу прийняти трилінійною [6]. Висхідна вітка цієї діаграми продовжується горизонтальною прямою до значень, що рівні $\varepsilon_{f c t}=3,5 \cdot 10^{-5}$, а низхідна вітка закінчується при деформаціях $\varepsilon_{f c t u}=2,5 \cdot 10^{-3}$ (рис. 2). Тут граничні деформації сталефібробетону вважаються рівними граничним деформаціям стержневої арматури для комбіновано армованих сталефібробетонних елементів.

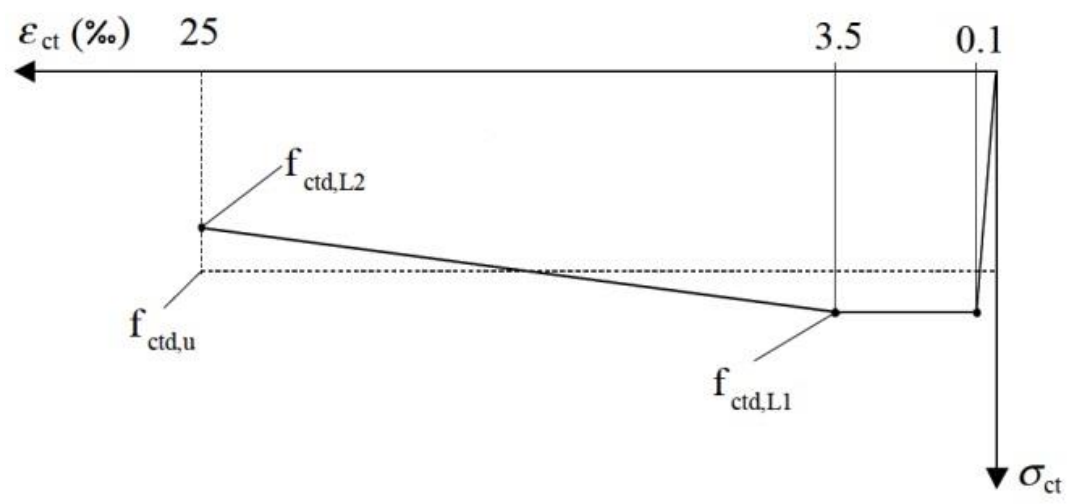

Рис. 2. Ідеалізована діаграма деформування сталефібробетону при розтягу, що пропонується для європейських норм асоціацією RILEM 
Сучасна методика розрахунку залізобетонних конструкцій, iз урахуванням нелінійного деформування матеріалів, у тому числі при розтягу, дозволяє доволі точно описувати роботу згинальних елементів на всіх етапах навантаження. Однак основна складність у застосуванні деформаційних моделей до розрахунку сталефібробетонних конструкцій полягає в описанні самих діаграм деформування. Повне їх описання вимагає значної кількості обчислень i, як правило, використання комп'ютерної техніки. У більшості випадків розрахунок потребує лише визначення несучої здатності елемента, без необхідності контролю напружено-деформованого стану перерізу на всіх етапах навантаження. Тому, як підтверджують дослідження, діаграму деформування бетону можна приймати трилінійною. Також, без суттєвої втрати у точності, такі діаграми можна приймати прямокутними з відповідними коефіцієнтами.

У статті пропонується силова методика розрахунку комбінованоармованих сталефібробетонних елементів за спрощених діаграм деформування стиснутої та розтягнутої зон (рис. 3). В даній методиці пропонується міцність на стиск приймати рівною міцності сталефібробетону, а не матриці. Також враховується повна робота сталефібробетону на розтяг, яка описується діаграмою на рис. 4.

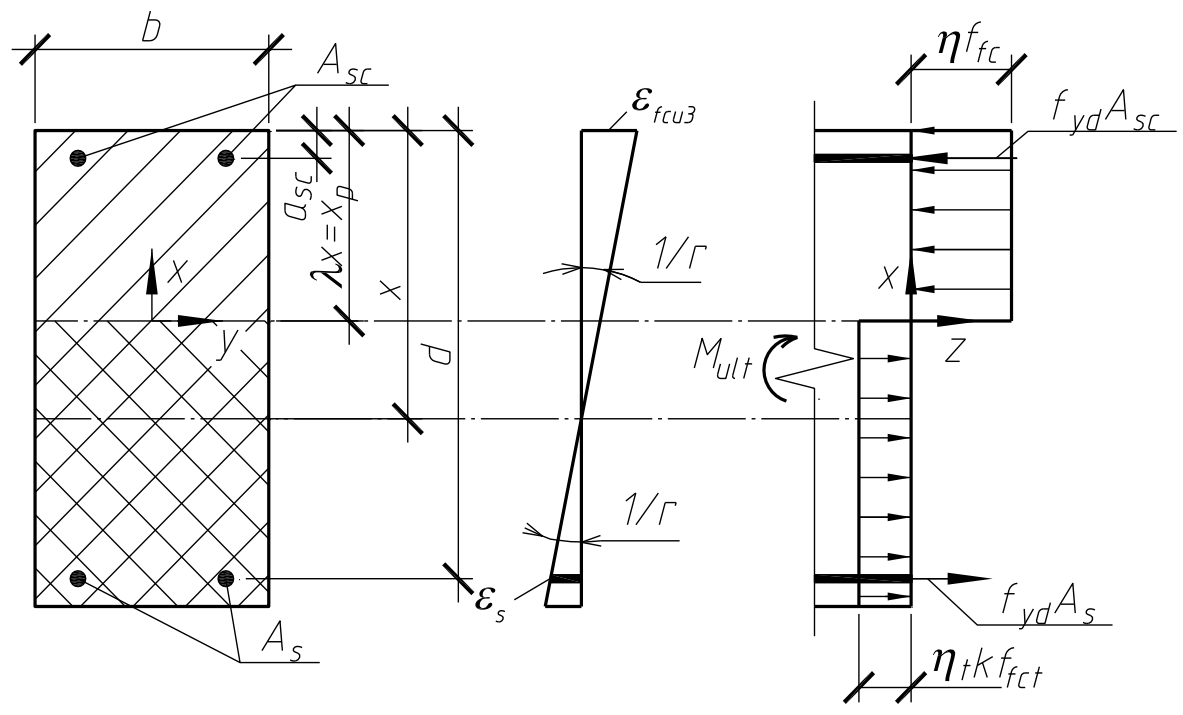

Рис. 3. Схема зусиль та епюри напружень у нормальному перерізі комбіновано-армованого сталефібробетонного елемента 


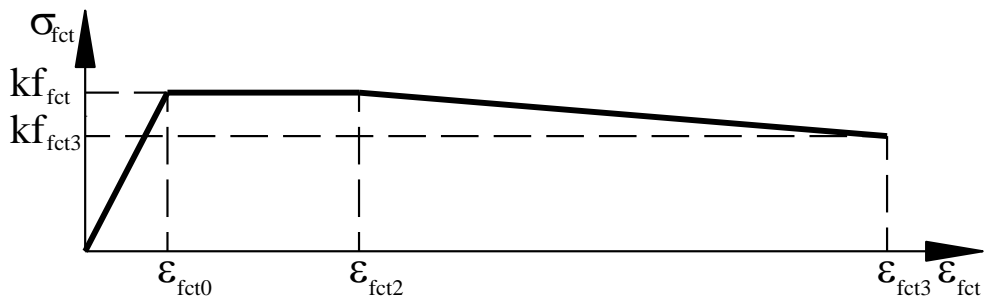

Рис. 4. Діаграма деформування СФБ при розтягу, прийнята в методиці

Значення несучої здатності згинальних фібробетонних елементів прямокутного перерізу з поздовжнім армуванням при $\xi=x_{p} / d \leq \xi_{R}$ визначається за виразом:

$$
M_{u l t}=\eta f_{f c} b x_{p}\left(d-0,5 \lambda x_{p}\right)+\eta_{t} k f_{f c t} b\left(h-x_{p}\right)\left(\frac{h-x}{2}-a\right)+f_{y d} A_{s c}\left(d-a_{s c}\right),
$$

де $a=h-d$, для дрібнозернистого бетону $\lambda=0,7 ; x_{p}$ - висота стиснутої зони перерізу за спрощеної прямокутної епюри напружень, яка для комбіновано-армованих елементів визначається за формулою:

$$
x_{p}=\frac{f_{y d} A_{s}-f_{y d} A_{s c}+\eta_{t} k f_{f c t} b h}{\left(\eta_{t} k f_{f c t} h+\eta f_{f_{c}}\right) b} .
$$

$k=0,56$ - коефіцієнт приведення прямокутної епюри напружень у розтягнутій зоні перерізу до дійсної криволінійної; $\eta=1$, для класів бетону до C60; $\eta_{t}$ - коефіцієнт повноти епюри напружень у розтягнутій зоні в перерізі сталефібробетонного елемента, приймається залежно від відношення опору фібробетону на розтяг при згині, до залишкової міцності фібробетону на розтяг при згині [7]:

$$
\eta_{t}=\left\{\begin{array}{c}
0,75 \text { nрu } 0,5 \leq f_{f c t 3} / f_{f c t}<0,7 ; \\
0,85 \text { nри } 0,7 \leq f_{f c t 3} / f_{f c t}<0,9 ; \\
0,95 \text { npu } 0,9 \leq f_{f c t 3} / f_{f c t}<1,1 ; \\
1,05 \text { npu } 1,1 \leq f_{f c t 3}<f_{f c t}<1,3 ; \\
1,15 \text { nри } 1,3 \leq f_{f c t 3} / f_{f c t} .
\end{array}\right.
$$


Фактична висота стиснутої зони $x$, визначається як $x=x_{p} / \lambda$.

Граничне значення висоти стиснутої зони визначаємо за умови:

$$
\xi_{R}=\frac{\varpi \varepsilon_{f c u, 3}}{\varepsilon_{f c u, 3}+\varepsilon_{s o}},
$$

де $\varepsilon_{s 0}=\frac{f_{y d}}{E_{s}}-$ розрахункове значення граничних відносних деформацій арматури; $\varepsilon_{f c u, 3}-$ граничні значення деформацій стиснутого сталефібробетону при використанні спрощеної діаграми деформування (рис. 3); - характеристика стиснутої зони фібробетону, яка приймається для дрібнозернистого бетону рівною 0,7 .

Для оцінки ефективності методики та дослідження ряду інших характеристик, було виконано дві серії експериментальних досліджень нерозрізних комбіновано-армованих сталефібробетонних балок. Методика дослідження та характер роботи балок у процесі випробувань, описані в роботах [8-10]. Для порівняння виконаємо розрахунки за методикою, що наведена в ДСТУ -Н Б В.2.6 - 218:2016 [4], та спрощеною силовою методикою.

Для застосування наведених методик використовуємо експериментально встановлені механічні характеристики матеріалів для балок другої серії: міцність сталефібробетону на стиск $f_{c k}=24,5 \mathrm{MПа;}$ міцність на розтяг $f_{c t}=2,35 \mathrm{M \Pi a} ; \varepsilon_{c l}=180,6 \times 10^{-5}$. Значення $a_{i}$ визначалися згідно методики НДІБК і відповідно склали: $a_{1}=2,534 ; a_{2}=-2,226 ; a_{3}=$ 0,$865 ; a_{4}=-0,189 ; a_{5}=0,016$. Розміри перерізу $b \times h=10 \times 16 \mathrm{~cm}$.

Армування для балок 2Б1-1,2 приймаємо двома стержнями Ø10А500С, для балок 2Б1-3 - двома стержнями Ø12А500С. Характеристики арматури: $E_{s}=195000$ МПа; $\sigma_{y}=508 \mathrm{MПа;} \varepsilon_{s 0}=0,00314$.

Вищезгаданою особливістю методики розрахунку СФБ елементів згідно 3 ДСТУ -Н Б В.2.6 - 218:2016 є те, що розрахунковий опір фібробетону на стиск $f_{c d}$ приймається рівним розрахунковому опору бетону матриці, який використовується для його отримання. Для дрібнозернистого бетону міцність матриці на стиск зазвичай значно менша, ніж сталефібробетону, що суттєво впливає на несучу здатність перерізу. У нашому випадку міцність матриці становила $f_{c k}=20,6$ МПа. Результати розрахунку балок представлено в таблиці 1. 
Порівняння результатів розрахунку несучої здатності балок другої серії

\begin{tabular}{|c|c|c|c|c|c|}
\hline $\begin{array}{l}\text { Марка } \\
\text { зразка }\end{array}$ & $\begin{array}{l}M_{u}^{\exp } \\
\mathrm{\kappa H}^{*} \mathrm{M}\end{array}$ & $\begin{array}{c}M_{u}^{\text {ДСТУ }}, \\
\kappa H^{*} \mathbf{M}\end{array}$ & $M_{u}^{\text {cил. }} \mathrm{\kappa H}^{*} \mathrm{M}$ & $M_{u}^{\text {ДCTY } / M_{u}^{e x p}}$ & $\begin{array}{c}M_{u}^{\text {cил. }} / \\
M_{u}^{\text {exp }}\end{array}$ \\
\hline 2 Б1-1 & 12,9 & \multirow{2}{*}{10,9} & \multirow{2}{*}{12,64} & 0,84 & 0,98 \\
\hline $2 Б 1-2$ & 13,1 & & & 0,83 & 0,96 \\
\hline 2 Б1-3 & 17,2 & 15,1 & 16,2 & 0,87 & 0,94 \\
\hline
\end{tabular}

\section{Висновки}

Як видно з представлених результатів, при визначенні несучої здатності перерізу, на кращу збіжність із експериментальними показують результати, визначені за допомогою спрощеної силової моделі. Очевидно, що врахування повної роботи сталефібробетону на стиск і на розтяг сприяє збільшенню точності розрахунку. Середня величина похибки не перевищує $3 . .5 \%$.

\section{References}

1. Droboshynets S.Ia., Vplyv povtornykh malotsyklovykh navantazhen na mekhanichni kharakterystyky stalefibrobetonu ta robotu zghynalnykh elementiv na yoho osnovi: dyss. kand. tekh. nauk. Lutsk: LNTU, 2006.

2. Bilozir V.V. Vplyv nyzkhidnoi vitky diahramy deformuvannia stalefibrobetonu za roztiahu na nesuchu zdatnist balok. Visnyk Lvivskoho natsionalnoho ahrarnoho universytetu. - Dubliany: LNAU, 2015. Vyp. № 16. S. 60-64.

3. Andriichuk $\mathrm{O}$. The influence of repeated loading on work of the steel fiber concrete drainage trays and pipes on the roads / Andriichuk O., Babich V., Yasyuk I., Uzhehov S. MATEC Web of Conferences, N 116, p 02001 (2017), 1-9.

4. DSTU-N B V.2.6-218:2016 Nastanova z proektuvannia ta vyhotovlennia konstruktsii iz dyspersno-armovanoho betonu. K: DP «UkrNDNC». 2017.

5. DBN V.2.6-98:2009 Konstruktsii budynkiv ta sporud. Betonni ta zalizobetonni konstruktsii. Osnovni polozhennia proektuvannia. K: Minrehionbud Ukrainy. 2009.

6. RILEM TC 162-TDF. "Design of steel fibre reinforced concrete using the $\sigma-\mathrm{w}$ method - principles and applications (Chairlady L. Vandewalle)." Materials and Structures, Vol. 35, No., June 2002, pp. 262-278.

7. Rekomendatsii $\mathrm{z}$ proektuvannia zalizobetonnykh konstruktsii fortyfikatsiinykh sporud: rekomendatsii. Ye.M. Babych, L.I. Dvorkin, V.V. Zhytkovskyi. Rivne: NUVHP, 2018.

8. Ninichuk M.V., Vplyv sposobu armuvannia stalevymy fibramy nerozriznykh zalizobetonnykh balok na yikh napruzheno deformovanyi stan/ Resursoekonomni materialy, konstruktsii, budivli ta sporudy: Zbirnyk naukovykh prats. - Rivne: NUVHP, 2015. Vyp. 31. S. 459-466. 
9. Ninichuk M.V., Vplyv kombinovanoho armuvannia na prohyny nerozriznykh zalizobetonnykh balok. Resursoekonomni materialy, konstruktsii, budivli ta sporudy: Zbirnyk naukovykh prats. Rivne: NUVHP, 2016. Vyp. 32. S. 220-225.

10. Andriichuk O.V. Eksperymentalni doslidzhennia roboty sterzhnevoi armatury $\mathrm{v}$ pererizakh kombinovano-armovanykh nerozriznykh zalizobetonnykh balok/ O.V. Andriichuk, M.V. Ninichuk // Suchasni tekhnolohii ta metody rozrakhunkiv u budivnytstvi: zbirnyk naukovykh prats. Lutsk, 2019. Vyp. 12. S. 3-12.

\section{Список використаної літератури}

1. Дробошинець С.Я., Вплив повторних малоциклових навантажень на механічні характеристики сталефібробетону та роботу згинальних елементів на його основі: дисс. канд. тех. наук. Луцьк: ЛНТУ, 2006.

2. Білозір В.В. Вплив низхідної вітки діаграми деформування сталефібробетону за розтягу на несучу здатність балок. Вісник Львівського національного аграрного університету. Дубляни: ЛНАУ, 2015. Випуск № 16. С. 60-64.

3. Andriichuk $O$. The influence of repeated loading on work of the steel fiber concrete drainage trays and pipes on the roads / Andriichuk O., Babich V., Yasyuk I., Uzhehov S. // MATEC Web of Conferences, N 116, p 02001 (2017), 1-9.

4. ДСТУ-Н Б В.2.6-218:2016. Настанова 3 проектування та виготовлення конструкцій із дисперсно-армованого бетону. К: ДП «УкрНДНЦ». 2017.

5. ДБН В.2.6-98:2009 Конструкції будинків та споруд. Бетонні та залізобетонні конструкції. Основні положення проектування. - К: Мінрегіонбуд України. - 2009.

6. RILEM TC 162-TDF. "Design of steel fibre reinforced concrete using the $\sigma-\mathrm{w}$ method - principles and applications (Chairlady L. Vandewalle)." Materials and Structures, Vol. 35, No., June 2002, pp. 262-278.

7. Рекомендації $з$ проектування залізобетонних конструкцій фортифікаційних споруд: рекомендації. Є.М. Бабич, Л.Й. Дворкін, В.В. Житковський. Рівне: НУВГП, 2018.

8. Нінічук М.В.; Вплив способу армування сталевими фібрами нерозрізних залізобетонних балок на ї напружено деформований стан/ Ресурсоекономні матеріали, конструкції, будівлі та споруди: Збірник наукових праць. Рівне: НУВГП, 2015. Випуск 31. С. 459-466.

9. Нінічук М.В.; Вплив комбінованого армування на прогини нерозрізних залізобетонних балок. Ресурсоекономні матеріали, конструкції, будівлі та споруди: Збірник наукових праць. Рівне: НУВГП, 2016. Випуск 32. С. 220-225.

10. Андрійчук О.В., Експериментальні дослідження роботи стержневої арматури в перерізах комбіновано-армованих нерозрізних залізобетонних балок/ О.В. Андрійчук, М.В. Нінічук. Сучасні технології та методи розрахунків у будівництві: збірник наукових праць. Луцьк, 2019. Випуск 12. С. 3-12. 